\title{
Identification of deregulation of apoptosis and cell cycle in neuroendocrine tumors of the lung via NanoString nCounter expression analysis
}

\author{
Robert Fred Henry Walter ${ }^{1,2}$, Robert Werner ${ }^{2}$, Saskia Ting ${ }^{2}$, Claudia Vollbrecht ${ }^{3}$, \\ Dirk Theegarten ${ }^{2}$, Daniel Christian Christoph ${ }^{4}$, Kurt Werner Schmid², Jeremias \\ Wohlschlaeger ${ }^{2}$ and Fabian Dominik Mairinger ${ }^{2}$ \\ ${ }^{1}$ Ruhrlandklinik, West German Lung Center, University Hospital Essen, University of Duisburg-Essen, Essen, Germany \\ 2 Institute of Pathology, University Hospital Essen, University of Duisburg-Essen, Essen, Germany \\ ${ }^{3}$ Institute of Pathology, University Hospital Cologne, Cologne, Germany \\ ${ }^{4}$ Department of Medical Oncology, West German Cancer Center, University Hospital Essen, University of Duisburg-Essen, \\ Essen, Germany \\ Correspondence to: Robert Fred Henry Walter, email: robert.walter@ruhrlandklinik.uk-essen.de \\ Keywords: small-cell lung cancer, large-cell neuroendocrine lung cancer, carcinoids, apoptosis, NanoString nCounter \\ Received: March 11, $2015 \quad$ Accepted: April 15, $2015 \quad$ Published: May 04, 2015
}

This is an open-access article distributed under the terms of the Creative Commons Attribution License, which permits unrestricted use, distribution, and reproduction in any medium, provided the original author and source are credited.

\section{ABSTRACT}

Background: Neuroendocrine tumors of the lung comprise typical (TC) and atypical carcinoids (AC), large-cell neuroendocrine cancer (LCNEC) and small-cell lung cancer (SCLC). Cell cycle and apoptosis are key pathways of multicellular homeostasis and deregulation of these pathways is associated with cancerogenesis.

Materials and Methods: Sixty representative FFPE-specimens (16 TC, 13 AC, 16 LCNEC and 15 SCLC) were used for mRNA expression analysis using the NanoString technique. Eight genes related to apoptosis and ten genes regulating key points of cell cycle were investigated.

Results: ASCL1, BCL2, CASP8, CCNE1, CDK1, CDK2, CDKN1A and CDKN2A showed lower expression in carcinoids compared to carcinomas. In contrast, CCNE1 and CDK6 showed elevated expression in carcinoids compared to carcinomas. The calculated $B C L 2 / B A X$ ratio showed increasing values from TC to SCLC.

Between SCLC and LCNEC CDK2, CDKN1B, CDKN2A and PNN expression was significantly different with higher expression in SCLC.

Conclusion: Carcinoids have increased CDK4/6 and CCND1 expression controlling RB1 phosphorylation via this signaling cascade. CDK2 and CCNE1 were increased in carcinomas showing that these use the opposite way to control RB1. BAX and BCL2 are antagonists in regulating apoptosis. $B C L 2$ expression increased over $B A X$ expression with increasing malignancy of the tumor from TC to SCLC.

\section{INTRODUCTION}

Neuroendocrine tumors (NET) of the lung comprise four entities with varying aggressiveness, ranging from well-differentiated typical carcinoids (TC), intermediate atypical carcinoids (AC) to poorly differentiated largecell neuroendocrine carcinomas (LCNEC) and small-cell lung cancer (SCLC) [1-3]. The 5-year survival of the NET subgroups differ significantly with TC having the best survival rates $(>87 \%)[4,5]$, followed by AC with $60 \%$
[6] and LCNEC with 15-57\% [7] and SCLC with less than $5 \%[8]$.

Cell cycle control and subsequent transcriptional regulation depends primarily on cyclin-dependent kinases (CDK), cyclin-dependent kinase inhibitors and cyclins that stimulate and inhibit each other in a highly timed manner to coordinate cell division and duplication [9]. The downstream target of these cell cycle mediators is RB1 (retinoblastoma 1, tumor suppressor) and chemotherapy efficacies were reported to depend on RB1 status in several 
Table 1: A total of 91 mRNA targets including 12 cell processes were investigated using a NanoString nCounter custom CodeSet.

\begin{tabular}{|c|c|}
\hline Cell Process & Investigated Targets \\
\hline Sox signaling & MYB, MYBBP1A, OCT4, PAX6, PCDHB, RBP1, SDCBP, SOX2, SOX4, SOX11, TEAD2 \\
\hline MET pathway & $G A B 1$, GRB2, MET, MST1R, PAX5 \\
\hline mTOR signaling & MTOR, RHOA, RICTOR, RPTOR \\
\hline angiogenesis & CRHR2, FIGF, FLT4, HIF1A, KDR, MMP3 \\
\hline apoptosis & ASCL1, BAX, BCL2, CASP8, CASP10, FAS, MDM2, TP53, PNN \\
\hline $\begin{array}{l}\text { neuroendocrine } \\
\text { differentiation }\end{array}$ & $C H G A, G A B B R 2, N C A M 1, N T S, R T N 1, S E M A 3 B, S Y P$ \\
\hline folate metabolism & ATIC, DHFR, FOLR1, FPGS, GART, GGT1, SLC19A1, TYMS \\
\hline DNA-repair & ERCC1, MLH1, MSH2, MSH6, XRCC1 \\
\hline cell cycle regulation & $C C N D 1, C C N E 1, C D K 1, C D K 2, C D K 4, C D K 6, C D K N 1 A, C D K N 1 B, C D K N 2 A, M I B 1$ \\
\hline tumor environment & LDHA, LDHB, LDHC, MAN2A1, MAN2B1, MAN2C1, TKTL1 \\
\hline $\begin{array}{c}\text { growth factors and } \\
\text { signaling }\end{array}$ & IGF1, IGF2, EGFR, FGFR1, AKT1, ALK, PTEN \\
\hline additional genes & CAT, CYP1A1, FN1, NES, NKX21, SOD1, STK11, TWSG1, UCHL1 \\
\hline Rference Genes & $A C T B, G A P D H, H P R T 1$ \\
\hline
\end{tabular}

cancer types [10-13]. New and specific cyclin inhibitors control the G1/S-phase checkpoint in RB1 active cells leading to a strong cytostatic effect in tumorous and non-tumorous cells $[13,14]$. One of these substances is PD-0332991, which is tested as single agent and as combination therapy regimen in clinical settings [13, 14]. This small molecule inhibitor, a pyridopyrimidine, is highly selective for CDK4/6 [14].

Apoptosis is important for multicellular homeostasis and evasion of apoptosis is another hallmark of cancer $[1,15,16]$. Pro-apoptotic regulators as BAX, P53 and caspases drive apoptosis in contrast to anti-apoptotic regulators such as BCL2 $[15,17,18]$.

Based on recent literature, this study was conducted to investigate the mRNA expression of apoptosis- and cell cycle-related genes and their impact on aggressiveness of NET of the lung by using the NanoString nCounter technology. The method allows enzyme-free digital detection of mRNAs, fusion genes or copy number variations $(\mathrm{CNV})$ in a high-throughput fashion $[19,20]$. Each investigated nucleic acid is targeted by a capture and a reporter probe that contain approximately 50 nucleotides (nt) that are complementary to the region of interest (ROI) $[19,21]$. Each capture probe carries a biotin-tag for immobilization and each reporter probe is labeled with a barcode of six fluorophores that is unique for each targeted sequence. The fluorescent barcodes are imaged and the software counts and decodes the barcodes. In this way, up to 800 different targets can be detected simultaneously in one analysis $[19,21]$. With this method, short target regions of approximately $100 \mathrm{nt}$ are reliably detectable in formalin-fixed, paraffin-embedded tissue (FFPE) and fragments of $100 \mathrm{nt}$ were reported to be detectable with nearly $100 \%$ efficiency [19, 22-24]. Importantly, Reis et al. proofed that the NanoString technique is able to analyze mRNA from FFPE tissue with results similar to fresh-frozen tissue [23]. This is of high interest, because FFPE is an important source for routine diagnostic in modern pathology connecting clinical follow-up data to large patient populations [22].

\section{RESULTS}

Sixty tumor specimens were investigated including 16 TC (27\%) and 13 AC (22\%), 16 LCNEC (27\%) and 15 SCLC $(25 \%)$ cases. Twenty-seven female (45\%) and 25 male patients $(42 \%)$ were investigated. For eight patients the gender remained inconclusive.

ASCL1 ( $\mathrm{p}=0.0016), B C L 2 \quad(\mathrm{p}<0.0001), C A S P 8$ $(\mathrm{p}=0.0030), C C N E 1 \quad(\mathrm{p}=0.0135), C D K 1 \quad(\mathrm{p}=0.0146)$, $C D K 2(\mathrm{p}=0.0114), C D K N 1 A(\mathrm{p}=0.0107)$ and $C D K N 2 A$ $(\mathrm{p}=0.0002)$ showed lower expression in carcinoids compared to carcinomas. In contrast, $C C N D 1(\mathrm{p}=0.0012)$ and CDK6 $(\mathrm{p}<0.0001)$ showed elevated expression in carcinoids compared to carcinomas. The results for $C D K 2$, $C D K 6, C C N D 1$ and $C D K N 2 A$ are summarized in figure 1. The calculated $B C L 2 / B A X$ ratio $(\mathrm{p}=0.0063)$ showed increasing values from TC to SCLC. The correlation of $B C L 2$ mRNA expression versus tumor type is shown in figure 2 in logarithmic and linear scale. Additionally, the calculated $B C L 2 / B A X$ ratio is shown in logarithmic scale in figure 2 .

Statistical analysis revealed a slightly higher expression of CDKN1A $(\mathrm{p}=0.0485)$ and $P N N(\mathrm{p}=0.0016)$ in AC compared to TC. Contrary, CASP8 ( $\mathrm{p}=0.0393)$ was slightly increased in TC compared to AC.

Between SCLC and LCNEC CDK2 ( $\mathrm{p}=0.0142)$, $C D K N 1 B(\mathrm{p}=0.0032), C D K N 2 A(\mathrm{p}=0.0291)$ and $P N N$ $(\mathrm{p}=0.0008)$ expression was significantly different with higher expression in SCLC. An overview of the results is charted in figure 3.

Minimal CCND1 $(\mathrm{p}=0.0035)$ expression correlated 

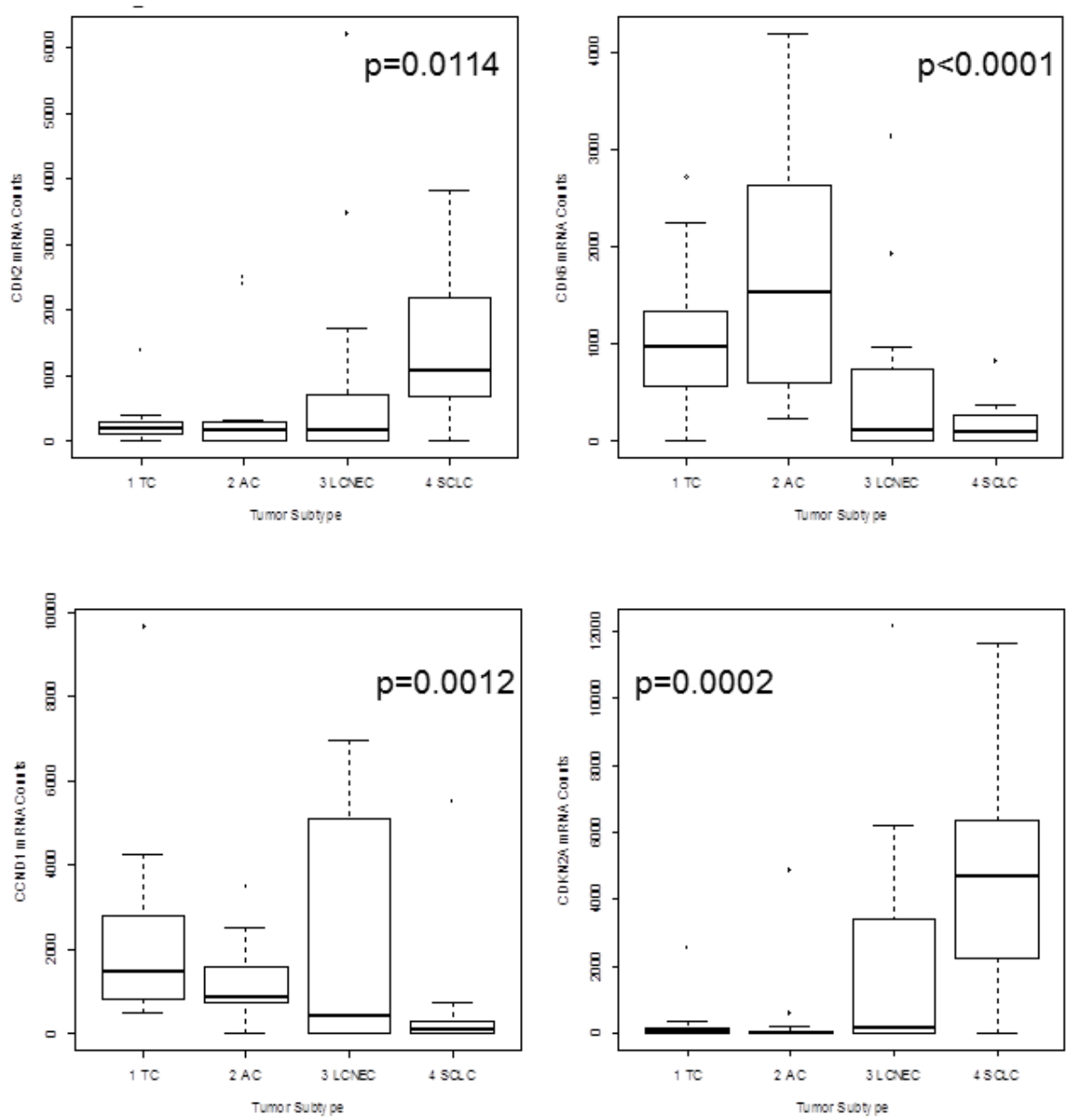

Figure 1: The boxplots show mRNA expression of $C D K 2, C D K 6, C C N D 1$ and $C D K N 2 A$ in neuroendocrine tumors of the lung. On the $\mathrm{x}$-axis the tumor subtype is shown and the $\mathrm{y}$-axis indicates the amount of detected mRNA transcripts. $C D K 2$ expression was higher in high-grade NET with highest expression in SCLC, whereas CDK6 showed significantly higher expression in carcinoids than in carcinomas. CCND1 expression decreased from TC to SCLC. CDKN2A was identified as prominent marker for aggressiveness of the tumor. Only high-grade tumors and aggressive carcinoids showed elevated $C D K N 2 A$ expression.
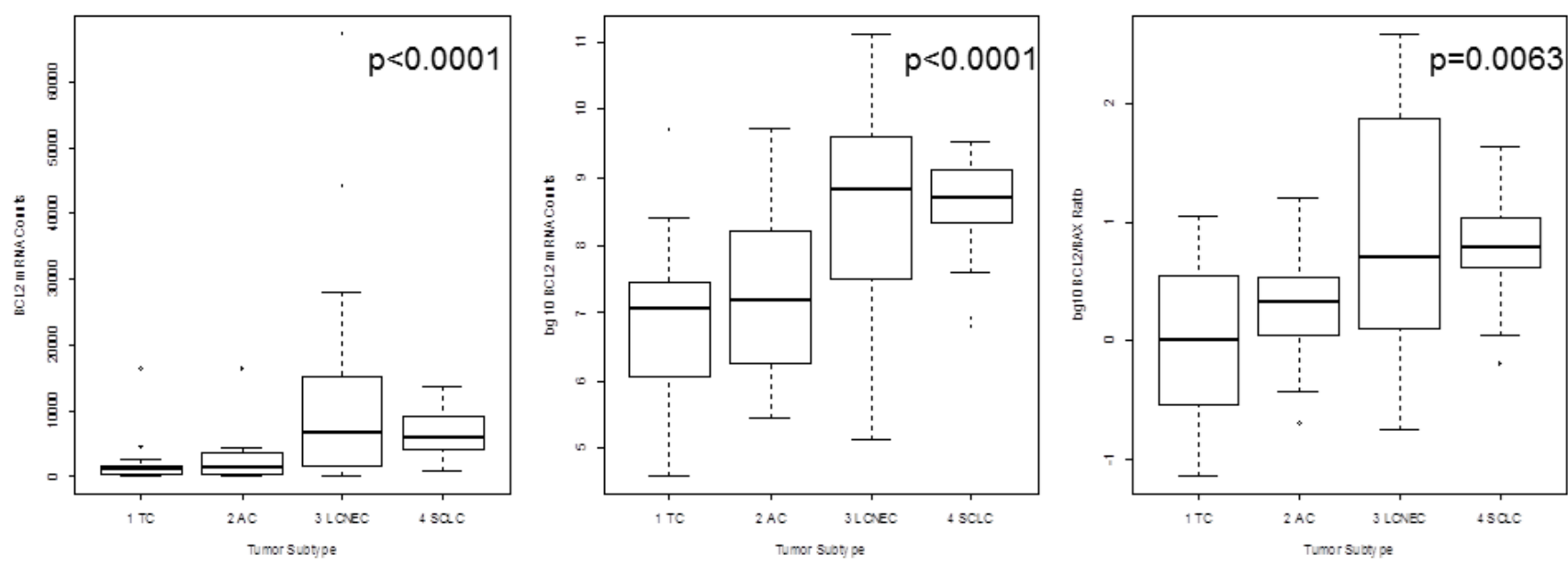

Figure 2: The mRNA expression of $B C L 2$ is shown in logarithmic and linear scale and additionally, the calculated $B C L 2 / B A X$ ratio is charted in logarithmic scale. The $x$-axis shows the tumor type, whereas the $y$-axis shows the detected mRNA transcripts. $B C L 2$ expression is minimal in TC and increased towards SCLC linking dedifferentiation with increasing proliferative activity. This is confirmed by the $B C L 2 / B A X$ ratio showing that most TC have an equilibrium between $B C L 2$ (driver of proliferation) and $B A X$ (driver of apoptosis), but increasing malignancy is accompanied by a reduction of apoptosis and increased proliferation. 
with lymph node invasion whereas, for $C D K N 2 A$ $(\mathrm{p}=0.0002)$ minimal to absent expression correlated with N0-status. Additionally, downregulation of CCND1 $(p=0.0234)$ expression to a minimum correlated with tumor-invasion into veins. For BCL2 $(\mathrm{p}=0.0391)$ lowered expression was found in $\mathrm{V} 0$-tumors.

\section{DISCUSSON}

The NanoString technique was able to specifically and sensitively analyze $91 \mathrm{mRNA}$-target transcripts from all investigated FFPE samples by using $100 \mathrm{ng}$ of total RNA per sample. The method relies on probes-pairs that are complementary to $100 \mathrm{nt}$ of the region of interest making it an ideal method for the analysis of degraded archival FFPE tissue [19, 22-24].
Here we present the differences between carcinoids and carcinomas regarding cell cycle control and apoptosis leading to differences in the aggressiveness of the clincopathological subtypes.

Achaete-scute complex homolog 1 (Drosophila) (ASCL1) belongs to the basic helix loop helix transcription factor family and mediates neuroendocrine differentiation $[25,26]$. Its expression is reported in fetal and adult neuroendocrine tissue and in various neuroendocrine tumors including SCLC $[25,26]$. Furthermore, Miki et al. reported high expression in carcinoid tumors of the lung [27]. In the present study, ASCL1 showed very high counts compared to the other investigated mRNA targets and was expressed in the majority of all NET of the lung with increasing expression from carcinoids to carcinomas (figure 4). Until now, little is known about the progenitor

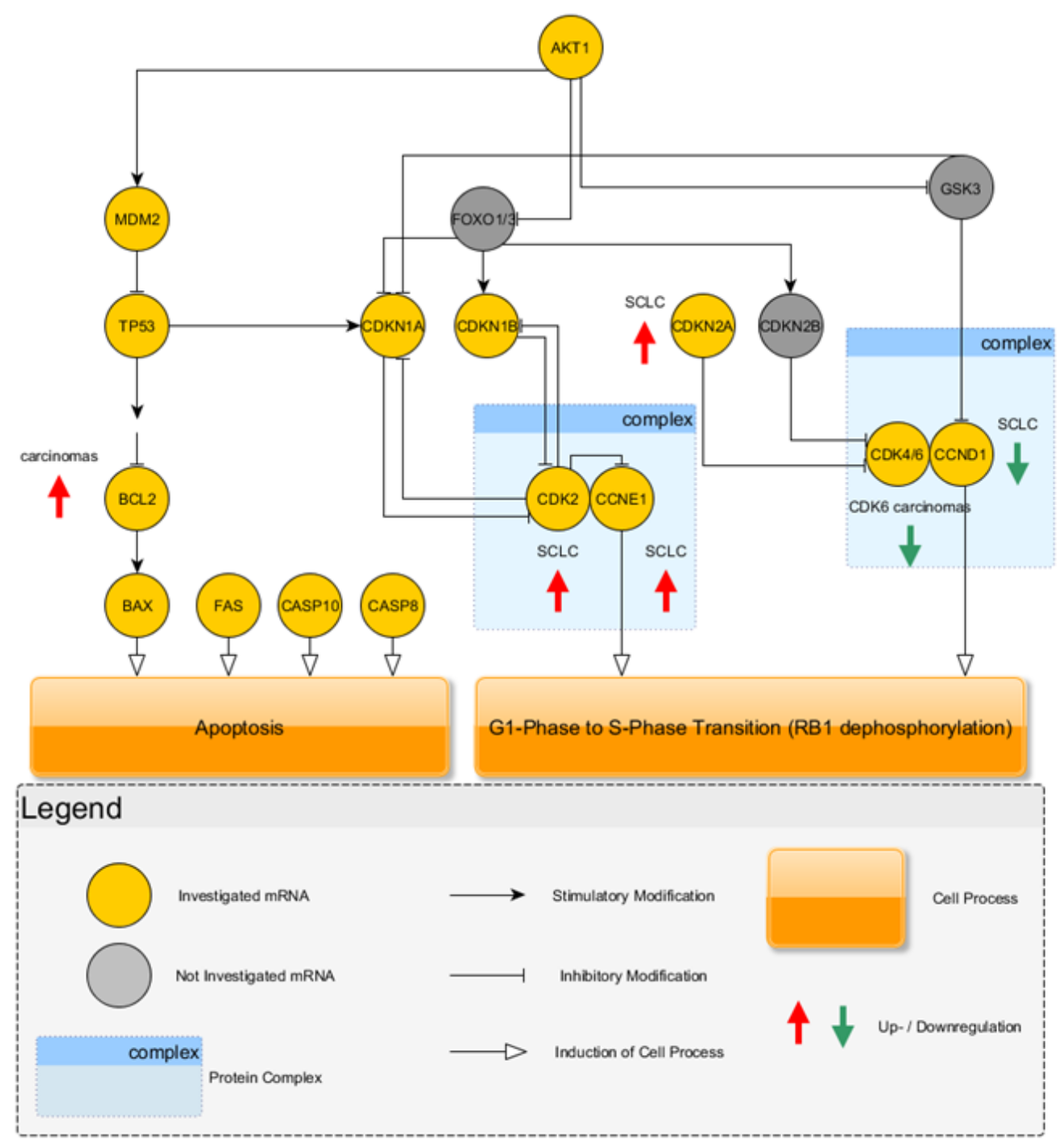

Figure 3: The investigated key mediators of apoptosis and cell cycle regulation are shown graphically. Carcinoids use the $C D K 4 / 6$ complex in combination with CCND1 to drive cell cycle progression. Instead, carcinomas showed a downregulation of these cell cycle mediators and additionally, the inhibitor of this section, CDKN2A, was increased in carcinomas. Carcinomas showed higher expression of $C D K 2$ and $C C N E 1$ indicating that cell cycle progression is driven by this complex. Furthermore, carcinomas showed elevated expression of $B C L 2$, an antagonist of apoptosis, which increased over $B A X$ expression leading to insensitivity to apoptosis. 
cells of NET in the lung, but it is speculated that they may arise from pulmonary neuroendocrine cells (PNEC), which account for approximately $0.4 \%$ of bronchial epithelial cells, but drive prenatal development of the lung as well as development of chemoreceptors in the adult lung [2, 2831]. Miki et al., suggested that ASCL1 may be a marker for early neuroendocrine differentiation in epithelial cells and that downregulation of ASCL1 by RNA interference led to significant growth reduction in tumors with high ASCL1 expression [27]. In conclusion, ASCL1 seems to a driving mediator of neuroendocrine (de-)differentiation in several tissues and distinct developmental key points, but its diagnostical relevance is limited due to its widespread appearance in all entities of neuroendocrine tumors.

One hallmark of cancer is the evasion of apoptosis and P53 is one key mediator regulating BCL2 and BAX, but inactive P53 is unable to control apoptosis or proliferation via this mechanism [1]. P53 inactivation via genetic alteration has been widely studies in LCNEC and SCLC [2]. TP53 mutations and loss of heterozygosity $(\mathrm{LOH})$ of $17 \mathrm{p} 13$ are frequent events in LCNEC $(>80 \%)$ and SCLC $(>90 \%)$, but rare in carcinoids $[2,32]$. BAX and BCL2 are antagonists regarding the regulation of apoptosis $[1,15]$. BAX drives apoptosis whereas BCL2 is a suppressor of this cell function $[1,15]$. A calculated ratio indicates the likelihood of cell to undergo apoptosis [33]. In the present paper, the median $B C L 2 / B A X$ ratio for TC showed equilibrium between $B A X$ and $B C L 2$ expression. With increasing malignancy, $B C L 2$ expression increased over $B A X$ leading to lowered apoptosis in most highgrade tumors. Furthermore, BCL2 showed significantly differential expression between carcinoids and carcinomas. Elevated expression was more common in carcinomas. In line with that, elevated expression of $B C L 2$ was a marker for invasiveness into veins.

Another hallmark of cancer is the deregulation of the cell cycle found in virtually all neoplasms $[1,16,34-$
36]. Cell cycle progression and proliferation are mainly controlled by the tumor suppressor RB1 at the G1/Sphase checkpoint $[34,35,37]$. RB1 is controlled by two upstream regulatory signaling cascades of CDKs and cyclins [34, 35]. CDKN2A, CDK4/6 and CCND1 are direct upstream regulators on the one side of the signaling cascade and on the other side CDKN1B, CDKN1A, CDK2 and CCNE1 are controlling RB1 phosphorylation [34, 35, 37].

Based on our results, carcinoids seem to use the signaling cascade via upregulation of $C D K 4 / 6$ and $C C N D 1$ expression to control RB1 phosphorylation. Additionally, $C D K N 2 A$, the regulatory inhibitor of $C D K 4 / 6$ [35], shows minimal to no expression in carcinoids. Palbociclib (PD-0332991), a pyridopyrimidine, is a highly selective CDK4/6 inhibitor that stops cell cycle progression at the G1/S-phase checkpoint in several in vivo and in vitro models and is currently tested in clinical settings [13, 14], indicating a potential, new therapy approach for carcinoid tumors of the lung. Until now, somatostatin analogues, such as octreotide acetate, were identified as effective compounds for patients with carcinoid tumors [38] and may show an enhanced effect in combination with cyclin inhibitors, because a cumulative effect was reported when therapy regimen contained palbociclib in combination with other drugs [13]. Flavopiridol, is a semisynthetic alkaloid and potent CDK inhibitor also inhibiting CDK6 and showed stronger induction of apoptosis and reduction of cell viability when combined with another cytostatic drug in an in vivo model [39].

For NSCLC a downregulation of $C D K N 2 A$ was reported [36] prooving that carcinoids use a similar way as NSCLC to drive G1/S-phase transition, instead cell cycle progression in LCNEC and SCLC is driven by the contrary pathway as summarized in figure 3 . The investigated carcinomas used the signaling cascade via increased expression of $C D K 2$ and $C C N E 1$ to drive cell

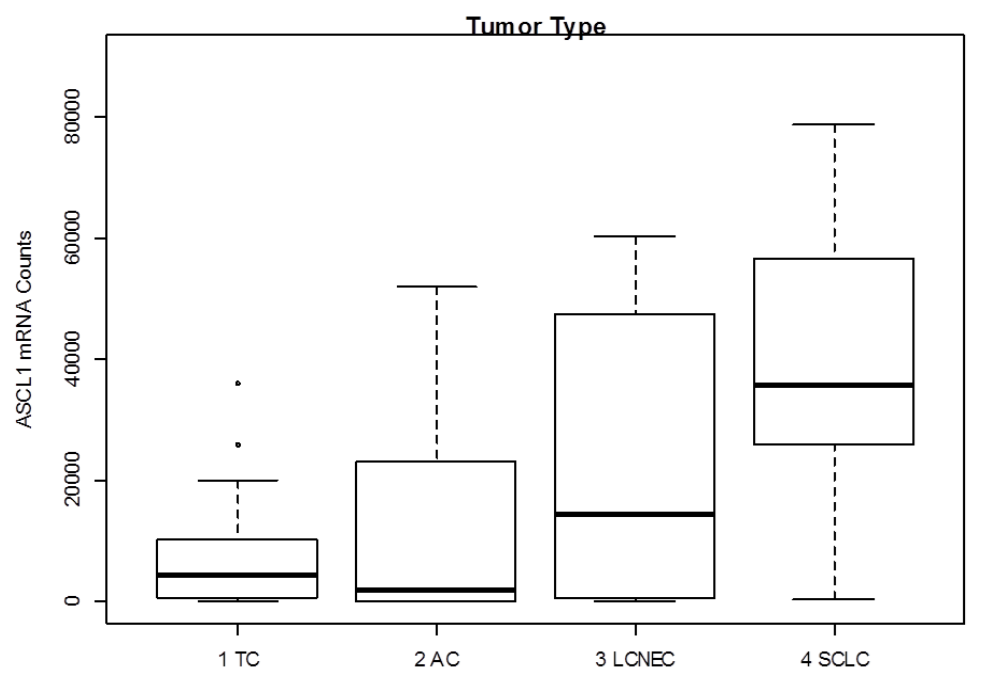

Figure 4: Gene expression levels of $A S C L 1$ in neuroendocrine tumors of the lung. $A S C L 1$ shows very high counts over all investigated entities. Median mRNA counts increase with increasing malignancy having the highest median counts in SCLC. 
cycle transition. High-grade tumors, especially SCLC, are associated with smoking [16] leading to an inactivation of P53 in up to $100 \%$ of all high-grade tumors [1]. CDKN1A is regulated by P53, but as reported, P53 activity is missing in nearly all high-grade tumors showing that this contributes to the use of the CDK2-CCNE1-pathway, because a downregulation of this pathway via CDKN1A is lacking. Flavopiridol also inhibits CDK2 [37] and may inhibit cell cycle progression in high-grade NETs.

$C D K N 2 A$ showed nearly no expression in low-grade tumors but highly elevated expression was found in most LCNEC and SCLC. Interestingly, one of the investigated AC showed a high expression of approximately 5,000 $C D K N 2 A$ mRNA counts and showed similar clinical behavior as an SCLC with fast progression of the disease and early death. Therefore, elevated $C D K N 2 A$ expression seems to be a potent biomarker for aggressiveness of neuroendocrine tumors of the lung, regardless of the subgroup. Additionally, expression of more than approximately $480 \mathrm{mRNA}$ counts was found as threshold for a potential lymph node invasion. Similarly, high expression of CDKN2A on the protein level correlated to poor differentiation, high grade and poor prognosis in advanced ovarian carcinomas and gastrointestinal stromal tumors $[40,41]$. For other malignancies, downregulation of CDKN2A expression was reported to correlate with poor outcome and high TNM stage [42], indicating a tissue and tumor specific regulation.

In contrast, CCND1 showed lowered expression in most LCNEC and in nearly all SCLC showing an inverted correlation to the malignancy of the tumors. Furthermore, minimal to absent expression was a marker for aggressiveness of the tumors regarding lymph node and vein invasion. In other malignancies, RB1 inactivation correlates with overexpression of $C C N D 1$ and downregulation of $C D K N 2 A$ [43].

In summary, deregulation of apoptosis and cell cycle mediators is an early event in several human cancers containing promising potential biomarkers amongst them with important impact on clinical decisions, such as prognosis, treatment and potential new therapy targets [44-47].

\section{MATERIALS AND METHODS}

Representative specimens of each tumor entity (16 TC and 13 AC, 16 LCNEC and 15 SCLC) were used for mRNA expression analysis. Patients that received chemotherapy before resection of tumor tissue specimens were excluded. The initial diagnosis was reevaluated by two experienced pathologists (JWO, DTH). Additional inclusion criteria were sufficient tumor material (at least $80 \%$ tumor cells) and minimal contamination by benign and stromal cells ( $<20 \%$ stromal cells/lymphocytes). Specimens were collected at the tumor bank at the Institute of Pathology, University Hospital Essen (Germany) from
2005 till 2012. Tumor classification is based on the WHO Classification Of Tumours guidelines (2004) [48] and TNM-staging is based on the UICC Classification of Malignant Tumours [49]. Clinical data were obtained from the patients' records. The study was conducted retrospectively for the identification of biomarkers to identify deregulation in neuroendocrine tumors regarding apoptosis and cell cycle. The study was approved by the ethical committee of the University Hospital Essen (ID: 13-5382-BO). The investigation conforms to the principles outlined in the declaration of Helsinki.

\section{RNA extraction and RNA integrity assessment}

Three to five paraffin sections with a thickness of $4 \mu \mathrm{m}$ per sample were deparaffinized with xylene prior to RNA extraction using the RNeasy FFPE kit (Qiagen, Hilden, Germany) according to the manufacturer's recommendations. Total RNA concentrations were measured using a Nanodrop 1000 instrument (Thermo Fisher Scientific, Waltham, USA). RNA integrity was assessed using an Agilent 2100 Bioanalyzer (Agilent Technologies, Santa Clara, USA) at the NanoString nCounter Core Facility at the University of Heidelberg, Germany. Smear analysis was performed using the Agilent 2100 expert software to determine the proportion of RNA $\geq 300$ nt within a given sample.

\section{NanoString codeSet design and expression quantification}

Various relevant genes involved in different tumorassociated signaling pathways and neuroendocrine differentiation were included in a custom CodeSet. The CodeSet was designed to contain a total of 91 genes with different signature genes for each subgroup (table 1). Nine genes associated with apoptosis (ASCL1, BAX, BCL2, CASP8, CASP10, FAS, MDM2, P53, PNN) and ten genes involved in cell cycle regulation (CCND1, CCNE1, CDK1, $C D K 2, C D K 4, C D K 6, C D K N 1 A, C D K N 1 B, C D K N 2 A$, $M I B 1)$ were investigated. Three potential reference genes ( $A C T B, G A P D H$, and HPRT1) were also included in the CodeSet for biological normalization. Probe sets for each gene in the CodeSet were designed and synthesized at NanoString Technologies, Seattle, USA.

Total RNA (100 ng) including miRNA from FFPE material was analyzed at the NanoString nCounter Core Facility at the University of Heidelberg, Germany.

\section{NanoString data processing and statistical analysis}

Raw NanoString counts for each gene were subjected to a technical normalization considering the 
counts obtained for positive control probe sets. After the technical normalization, a biological normalization using the three reference genes included in the CodeSet was performed.

All statistical analyses were performed with the $\mathrm{R}$ statistical programming environment (v2.15.2). For dichotomous factors such as gender and expression level the Wilcoxon Mann-Whitney rank sum test was applied. The Kruskal-Wallis test was used to correlate tumor type and gene expression. The same test was also used to perform subgroup analysis between low- and high-grade tumors, atypical and typical carcinoids and SCLC versus LCNEC. Correlations between gene expression and TNMstages were analyzed by Spearman's rank correlation test.

The level of statistical significance was defined as $\mathrm{p} \leq 0.05$.

\section{ACKNOWLEDGMENTS}

We thank the nCounter Core Facility Heidelberg for providing the nCounter system and related services.

\section{CONFLICTS OF INTEREST}

All authors have read and approved the manuscript.

All authors disclose any affiliations that are considered to be relevant and important with any organization that to our knowledge has any direct interest in the subject matter discussed.

\section{GRANT SUPPORT}

The study was not supported by any grant.

\section{REFERENCES}

1. Brambilla E, Negoescu A, Gazzeri S, Lantuejoul S, Moro D, Brambilla C and Coll JL. Apoptosis-related factors p53, Bcl2, and Bax in neuroendocrine lung tumors. The American journal of pathology. 1996; 149:1941-1952.

2. Swarts DR, Ramaekers FC and Speel EJ. Molecular and cellular biology of neuroendocrine lung tumors: evidence for separate biological entities. Biochimica et biophysica acta. 2012; 1826:255-271.

3. Rekhtman N. Neuroendocrine tumors of the lung: an update. Archives of pathology \& laboratory medicine. 2010; 134:1628-1638.

4. Thomas CF, Jr., Tazelaar HD and Jett JR. Typical and atypical pulmonary carcinoids : outcome in patients presenting with regional lymph node involvement. Chest. 2001; 119:1143-1150.

5. Travis WD, Rush W, Flieder DB, Falk R, Fleming MV, Gal AA and Koss MN. Survival analysis of 200 pulmonary neuroendocrine tumors with clarification of criteria for atypical carcinoid and its separation from typical carcinoid.
The American journal of surgical pathology. 1998; 22:934944.

6. Beasley MB, Thunnissen FB, Brambilla E, Hasleton P, Steele R, Hammar SP, Colby TV, Sheppard M, Shimosato Y, Koss MN, Falk R and Travis WD. Pulmonary atypical carcinoid: predictors of survival in 106 cases. Human pathology. 2000; 31:1255-1265.

7. Iyoda A, Hiroshima K, Nakatani $Y$ and Fujisawa T. Pulmonary large cell neuroendocrine carcinoma: its place in the spectrum of pulmonary carcinoma. The Annals of thoracic surgery. 2007; 84:702-707.

8. Shepherd FA, Crowley J, Van Houtte P, Postmus PE, Carney D, Chansky K, Shaikh Z, Goldstraw P, International Association for the Study of Lung Cancer International Staging C and Participating I. The International Association for the Study of Lung Cancer lung cancer staging project: proposals regarding the clinical staging of small cell lung cancer in the forthcoming (seventh) edition of the tumor, node, metastasis classification for lung cancer. Journal of thoracic oncology : official publication of the International Association for the Study of Lung Cancer. 2007; 2:10671077.

9. Morgan DO. Cyclin-dependent kinases: engines, clocks, and microprocessors. Annual review of cell and developmental biology. 1997; 13:261-291.

10. Aparicio A, Den RB and Knudsen KE. Time to stratify? The retinoblastoma protein in castrate-resistant prostate cancer. Nature reviews Urology. 2011; 8:562-568.

11. Ertel A, Dean JL, Rui H, Liu C, Witkiewicz AK, Knudsen $\mathrm{KE}$ and Knudsen ES. RB-pathway disruption in breast cancer: differential association with disease subtypes, disease-specific prognosis and therapeutic response. Cell cycle. 2010; 9:4153-4163.

12. Knudsen ES and Knudsen KE. Tailoring to RB: tumour suppressor status and therapeutic response. Nature reviews Cancer. 2008; 8:714-724.

13. McClendon AK, Dean JL, Rivadeneira DB, Yu JE, Reed CA, Gao E, Farber JL, Force T, Koch WJ and Knudsen ES. CDK4/6 inhibition antagonizes the cytotoxic response to anthracycline therapy. Cell cycle. 2012; 11:2747-2755.

14. DiRocco DP, Bisi J, Roberts P, Strum J, Wong KK, Sharpless N and Humphreys BD. CDK4/6 inhibition induces epithelial cell cycle arrest and ameliorates acute kidney injury. American journal of physiology Renal physiology. 2014; 306:F379-388.

15. Beverly LJ, Lockwood WW, Shah PP, Erdjument-Bromage $\mathrm{H}$ and Varmus $\mathrm{H}$. Ubiquitination, localization, and stability of an anti-apoptotic BCL2-like protein, BCL2L10/BCLb, are regulated by Ubiquilin1. Proceedings of the National Academy of Sciences of the United States of America. 2012; 109:E119-126.

16. Wang DG, Johnston CF, Sloan JM and Buchanan KD. Expression of Bcl-2 in lung neuroendocrine tumours: comparison with p53. The Journal of pathology. 1998; 
$184: 247-251$.

17. Kikuchi M, Kuroki S, Kayama M, Sakaguchi S, Lee KK and Yonehara S. Protease activity of procaspase- 8 is essential for cell survival by inhibiting both apoptotic and nonapoptotic cell death dependent on receptor-interacting protein kinase 1 (RIP1) and RIP3. The Journal of biological chemistry. 2012; 287:41165-41173.

18. Bold RJ, Termuhlen PM and McConkey DJ. Apoptosis, cancer and cancer therapy. Surgical oncology. 1997; 6:133142.

19. Geiss GK, Bumgarner RE, Birditt B, Dahl T, Dowidar N, Dunaway DL, Fell HP, Ferree S, George RD, Grogan T, James JJ, Maysuria M, Mitton JD, Oliveri P, Osborn JL, Peng $\mathrm{T}$, et al. Direct multiplexed measurement of gene expression with color-coded probe pairs. Nature biotechnology. 2008; 26:317-325.

20. Waggott D, Chu K, Yin S, Wouters BG, Liu FF and Boutros PC. NanoStringNorm: an extensible R package for the pre-processing of NanoString mRNA and miRNA data. Bioinformatics. 2012; 28:1546-1548.

21. Beaume M, Hernandez D, Docquier M, Delucinge-Vivier $\mathrm{C}$, Descombes $\mathrm{P}$ and Francois P. Orientation and expression of methicillin-resistant Staphylococcus aureus small RNAs by direct multiplexed measurements using the nCounter of NanoString technology. Journal of microbiological methods. 2011; 84:327-334.

22. Walter RF, Mairinger FD, Wohlschlaeger J, Worm K, Ting S, Vollbrecht C, Kurt Werner S and Hager T. FFPE tissue as a feasible source for gene expression analysis--a comparison of three reference genes and one tumor marker. Pathology, research and practice. 2013; 209:784-789.

23. Reis PP, Waldron L, Goswami RS, Xu W, Xuan Y, PerezOrdonez B, Gullane P, Irish J, Jurisica I and Kamel-Reid S. mRNA transcript quantification in archival samples using multiplexed, color-coded probes. BMC biotechnology. 2011; 11:46.

24. Mairinger FD, Walter RF, Werner R, Christoph DC, Ting S, Vollbrecht C, Zarogoulidis K, Huang H, Li Q, Schmid KW, Wohlschlaeger J and Zarogoulidis P. Activation of angiogenesis differs strongly between pulmonary carcinoids and neuroendocrine carinomas and is crucial for carcinoid tumourgenesis. Journal of Cancer. 2014; 5:465-471.

25. Fujiwara $T$, Hiramatsu $M$, Isagawa $T$, Ninomiya $H$, Inamura $\mathrm{K}$, Ishikawa $\mathrm{S}$, Ushijima $\mathrm{M}$, Matsuura $\mathrm{M}$, Jones MH, Shimane M, Nomura H, Ishikawa Y and Aburatani H. ASCL1-coexpression profiling but not single gene expression profiling defines lung adenocarcinomas of neuroendocrine nature with poor prognosis. Lung Cancer. 2012; 75:119-125.

26. La Rosa S, Marando A, Gatti G, Rapa I, Volante M, Papotti M, Sessa F and Capella C. Achaete-scute homolog 1 as a marker of poorly differentiated neuroendocrine carcinomas of different sites: a validation study using immunohistochemistry and quantitative real-time polymerase chain reaction on 335 cases. Human pathology.
2013; 44:1391-1399.

27. Miki M, Ball DW and Linnoila RI. Insights into the achaetescute homolog-1 gene (hASH1) in normal and neoplastic human lung. Lung Cancer. 2012; 75:58-65.

28. Bensch KG, Corrin B, Pariente R and Spencer H. Oatcell carcinoma of the lung. Its origin and relationship to bronchial carcinoid. Cancer. 1968; 22:1163-1172.

29. Warburton D, Schwarz M, Tefft D, Flores-Delgado G, Anderson KD and Cardoso WV. The molecular basis of lung morphogenesis. Mechanisms of development. 2000; 92:55-81.

30. Linnoila RI. Functional facets of the pulmonary neuroendocrine system. Laboratory investigation; a journal of technical methods and pathology. 2006; 86:425-444.

31. Boers JE, den Brok JL, Koudstaal J, Arends JW and Thunnissen FB. Number and proliferation of neuroendocrine cells in normal human airway epithelium. American journal of respiratory and critical care medicine. 1996; 154:758-763.

32. Koreth J, Bakkenist CJ and McGee JO. Chromosomes, 11Q and cancer: a review. The Journal of pathology. 1999; 187:28-38.

33. Kobayashi Y, Tokuchi Y, Hashimoto T, Hayashi M, Nishimura H, Ishikawa Y, Nakagawa K, Sato Y, Takahashi A and Tsuchiya E. Molecular markers for reinforcement of histological subclassification of neuroendocrine lung tumors. Cancer science. 2004; 95:334-341.

34. Nishi K, Inoue H, Schnier JB and Rice RH. Cyclin D1 downregulation is important for permanent cell cycle exit and initiation of differentiation induced by anchoragedeprivation in human keratinocytes. Journal of cellular biochemistry. 2009; 106:63-72.

35. Russo AA, Tong L, Lee JO, Jeffrey PD and Pavletich NP. Structural basis for inhibition of the cyclin-dependent kinase Cdk6 by the tumour suppressor p16INK4a. Nature. 1998; 395:237-243.

36. Coe BP, Lockwood WW, Girard L, Chari R, Macaulay C, Lam S, Gazdar AF, Minna JD and Lam WL. Differential disruption of cell cycle pathways in small cell and nonsmall cell lung cancer. British journal of cancer. 2006; 94:1927-1935.

37. Dickson MA. Molecular pathways: CDK4 inhibitors for cancer therapy. Clinical cancer research : an official journal of the American Association for Cancer Research. 2014; 20:3379-3383.

38. Gridelli C, Rossi A, Airoma G, Bianco R, Costanzo R, Daniele B, Chiara GD, Grimaldi G, Irtelli L, Maione P, Morabito A, Piantedosi FV and Riccardi F. Treatment of pulmonary neuroendocrine tumours: state of the art and future developments. Cancer treatment reviews. 2013; 39:466-472.

39. Song Y, Xin X, Zhai X, Xia Z and Shen K. Sequential combination of flavopiridol with Taxol synergistically suppresses human ovarian carcinoma growth. Archives of 
gynecology and obstetrics. 2014.

40. Khouja MH, Baekelandt M, Nesland JM and Holm R. The clinical importance of Ki-67, p16, p14, and p57 expression in patients with advanced ovarian carcinoma. International journal of gynecological pathology : official journal of the International Society of Gynecological Pathologists. 2007; 26:418-425.

41. Steigen SE, Bjerkehagen B, Haugland HK, Nordrum IS, Loberg EM, Isaksen V, Eide TJ and Nielsen TO. Diagnostic and prognostic markers for gastrointestinal stromal tumors in Norway. Modern pathology : an official journal of the United States and Canadian Academy of Pathology, Inc. 2008; 21:46-53.

42. Ito S, Ohga T, Saeki H, Watanabe M, Kakeji Y, Morita M, Yamada T and Maehara Y. Promoter hypermethylation and quantitative expression analysis of CDKN2A (p14ARF and p16INK4a) gene in esophageal squamous cell carcinoma. Anticancer research. 2007; 27:3345-3353.

43. Mizuarai S, Machida T, Kobayashi T, Komatani H, Itadani $\mathrm{H}$ and Kotani $\mathrm{H}$. Expression ratio of CCND1 to CDKN2A mRNA predicts RB1 status of cultured cancer cell lines and clinical tumor samples. Molecular cancer. 2011; 10:31.

44. Chu IM, Hengst L and Slingerland JM. The Cdk inhibitor p27 in human cancer: prognostic potential and relevance to anticancer therapy. Nature reviews Cancer. 2008; 8:253267.

45. Shariat SF, Ashfaq R, Sagalowsky AI and Lotan Y. Association of cyclin D1 and E1 expression with disease progression and biomarkers in patients with nonmuscleinvasive urothelial cell carcinoma of the bladder. Urologic oncology. 2007; 25:468-475.

46. Cooper WA, Lam DC, O'Toole SA and Minna JD. Molecular biology of lung cancer. Journal of thoracic disease. 2013; 5:S479-490.

47. Shaye A, Sahin A, Hao Q, Hunt K, Keyomarsi K and Bedrosian I. Cyclin E deregulation is an early event in the development of breast cancer. Breast cancer research and treatment. 2009; 115:651-659.

48. Travis WD, World Health Organization., International Agency for Research on Cancer., International Association for the Study of Lung Cancer. and International Academy of Pathology. (2004). Pathology and genetics of tumours of the lung, pleura, thymus and heart. (Lyon Oxford: IARC Press Oxford University Press (distributor)).

49. Sobin LH, Gospodarowicz MK, Wittekind C and International Union against Cancer. (2010). TNM classification of malignant tumours. (Chichester, West Sussex, UK ; Hoboken, NJ: Wiley-Blackwell). 